\title{
Neurotechnology as a tool for inducing and measuring altered states of consciousness in transpersonal psychotherapy
}

\author{
Raul Valverde \\ Concordia University, raul.valverde@concordia.ca
}

\begin{abstract}
Transpersonal psycho therapy is based on transpersonal psychology and considers that the psyche is multidimensional and that there are several "levels of consciousness" and each has different characteristics and is governed by different laws. Transpersonal psychology is the study of human nature and proceeds on the assumption that human beings possess potentials that exceed the limits of their ego and integrate the spiritual experience within a broader understanding of the human psyche and consciousness. Altered states of consciousness have been used as psychotherapy in transpersonal psychology for decades. Although there are very well known techniques to induce altered state of consciousness as holotropic breathwork, neurotechnology offers an alternative way not only to induce these states for transpersonal therapy but also to measure the level of a state of consciousness. The objective of this article is to provide a review of the main concepts of neurotechnology and the main technologies that can be used to induce and measure altered state of consciousness for transpersonal psychotherapy.
\end{abstract}

Keywords: Altered states of consciousness, neurotechnology, biofeedback, transpersonal therapy

\section{Introduction}

Interest in neutechnological devices has grown strongly since the release of 1986's classic text of Michael Hutchison "Megabrain" (1986). Besides neurotechnological machines, the industry has developed a range of related devices including peripherals-tapes, subliminal tapes, hypnoperipheral processing, sound meditation devices and altered state induction software programs for personal computers, etc. It seems like neurotechnology combined with contemporary psychology may seem to be revolutionary but its roots are much older as humanity has made many attempts in the past to involve consciousness with technology. The flashing LEDs in a light and sound machine can be traced back to the old practice of starting a fire in order to induce trance. Sound recordings of brain entrainment undoubtedly have their roots in the ritual singing and shamanic use of wind instruments.

This current era of neurotechnology was born from the experiments made in biofeedback that resulted in the work of some researchers of consciousness as Masters \& Houston (1966) that created the AVE (an abbreviation of Audio Visual Environment) that is one of the first electronic brain entrainment devices. The AVE was the first device to use visual and auditory stimuli as a means of altering consciousness. Not much different that many of 
audiovisual devices of today, the AVE consisted of a wrap-around screen and headphones to bomb the sense in these two stimuli.

These signals generated by AVE devices and detectable by electroencephalogram (EEG) tests at specific frequency ranges; seem to vary from one state of consciousness to another for their users. The products of neurotechnology appear to make possible to "tune" the brain to these different alternating frequencies, and in turn achieve new psychological states. When you "tune" into these frequencies at a slower pace, our thought processes and central nervous system are altered, causing the brain to fall into a deep level of activity. In addition, when one is tuned to a frequency faster and a higher range, the wave activity can have a highly stimulating effect on the brain.

Altered states of consciousness have been used as a therapy for modern psychological paradigms as transpersonal psychology (Valverde 2015). Although there are several techniques such as holotropic breathing used to induce these altered states of consciousness, neurotechnology offers a more easy to control alternative to the transpersonal therapies.

In order to understand neurotechnology, this review begins with an introduction to the technologies that made possible the modern neurotechnology including biofeedback, quantum physics, quantum biofeedback, theory of consciousness, principles and applications of neurotechnology for inducing altered states of consciousness in transpersonal therapies.

\section{Biofeedback}

Biofeedback literally means, "responding to life". The work of Miller opened the doors to research processes in biofeedback. Miller (1978) constructed an apparatus equipped with sensitive electrodes connected to a monitor on which the patient could see how the skin temperature behaved, teaching patients to relax and concentrate to get it to relax the smooth vasculature of vessels peripheral blood in order to descend skin temperature.

Biofeedback is the process by which a person learns to influence involuntary body processes to receive physiological data from an electronic device that continuously monitors certain physiological parameters. It is a way of measuring the response to the physical, emotional, mental and spiritual stresses of life. Bodies under high stress are more prone to physical discomfort and even illness. The biofeedback response occurs when the body receives new information about their status (e.g, get 'feedback') and make healthy adjustments to reduce stress and tension. The result is a reduction of the nervous activity and increased vitality. Users of the feedback report a greater sense of well-being and joy.

Biofeedback neurotechnology instruments measure muscle activity, skin temperature, electrodermal activity (sweat gland activity), respiration, heart rate, heart rate variability, blood pressure, brain electrical activity and blood flow. These technologies are able to capture analog electrical signals from the body and translate those signals into meaningful information through complex algorithmic software that a technician can then decipher. Research shows that biofeedback, alone and in combination with other therapies is effective for treating a variety of medical and psychological disorders. Biofeedback is currently used by doctors, nurses, psychologists, counselors, physical therapists, occupational therapists and other professionals. Biofeedback is also used by computer scientists in order to build human computer interactions (Valverde 2011). 
Studies by Jonas and Levin (1999) show that biofeedback is ideal for patients that are looking for therapies that are softer, less toxic and less invasive. The biofeedback technique is applied in the field of psychology for treating phobias, neurosis, anxiety, depression and insomnia.

\section{Quantum physics}

What we are able to perceive with our five senses is not reality. Quantum physics has shown that space and time are illusions of perception. Our body cannot really be a reality if it does not occupy most of the space it seems to occupy; an experiment made at the University of Manchester revealed the shape of the interior of an atom is almost entirely empty space. The question then became how we could possibly make the world around us see us if this is the case (Russell et al 1993).

Our true consciousness does not exist in our brains or in our bodies, but this illusion of our individual bodies along with the misinformation of our true origins has manifested the idea that we all think independently from one another. With this understanding, it seems possible to scientifically explain telepathy, clairvoyance, spiritual mediums related to the transfer of information between sources without physical means of communication phenomena. But when we understand that there is a common spiritual bond between all things in the universe and that we are all part of a divine intelligence, this simple understanding fills all the holes in modern religions and predictions about the future and literally every occurrence of events (Russell et al 1993).

According to quantum physics, the physical world and its reality, it's just a recreation of the observed. We created the body and reality, as we create the experience of our world in its different manifestations dimensional. In its essential state (atomic or cosmic subquantum micro), the body is made of energy and information, not solid matter, this is only a meager level of perception. According to Tornell (2001), this is energy and information arising from the endless fields of energy and information spanning the entire universal creation.

When looking at the electronic microscope, we are looking at our microcosm, we then can see how the quantum particles manifest virtually as a symphony and intelligent orchestration at speeds much higher than the visible light, this quantum view also represents the immutability of our macrocosm. In this reality, each individual inhabits a reality that is beyond all change, as more deep within us without the knowledge of our three-dimensional or physical outer senses. There is a core of being, an energy field that creates immortality in nature, and manifests as the physical body. This core is the essential being or soul, primordial seed, which is contained in an atom called seed. We are seeds of eternal essence at this stage of quantum eternity.

This is the seed based on new paradigms posed by Max Planck, J. Clark Maxwell, Faraday, Heisenberg, Schrodinger, Bohr, Einstein, S. Hawking, among many other pioneers of quantum mechanics. They understood that the way to see the world in their time was very wrong. Within the quantum paradigm, we are more than our physical body; our true self and personality are governed by the rules of the principle of cause and effect and are embedded into a body for the duration of human life. The field of human life is open and unlimited in its deeper quantum level, this means that we are immortal and timeless. Once we identify with the eternal reality that is consistent with quantum vision of the universe, we will enter the new paradigms of quantum consciousness. Everything that exists has a natural vibration to its atoms all the way up to the immensity of the universe to show a simple connection between land and our bodies. 


\section{Consciousness}

Being aware is to realize everything that happens around you. It is as if in the previous moment you take an action, before acting you ask yourself: Is it right what I do? and someone who "is not you" answers only "yes" or "no" (Hawnser 1997). Our mind before ordering an action to the physical body, studies the elements it has to do with the action: knowledge, physical strength, skill, etc. Consider the risks, the consequences, the material benefits that give us the results of the act, also any loss and damage and / or suffering that the action may bring to our selves or third parties (Hawnser 1997).

Edelman and Tonomi (2000) think that the whole universe is actually one living organism with full conscious awareness of self. The consciousness of our universe is responsible for the form and purpose that all matter assumes. Carl Jung (1981) found that there is a collective unconscious connected to all humans. This means that all humanity shares a single mind with one another. This is evident in the world through accounts of shared mythology and symbols. This collectivity is a global example of the unconscious mind of the human body in which billions of cells share a similar signal. Human consciousness is an electromagnetic energy field; this could explain many paranormal phenomena such as telepathy and clairvoyance that seem to probe this.

Most Western scientists assume that consciousness is produced in some form by the brain. There is of course some evidence for that position. There is evidence of common sense in our daily lives. When we drink too much alcohol or takes a hard hit to the head, we do not think clearly. We also have more sophisticated tests of the relationship between the brain and consciousness. In fact all the theories of consciousness during the last century has been supported by psychologists who have been moving towards the materialism that characterized the nineteenth-century physics based on Newton's classical mechanics. These have been trying to show that consciousness is only the functioning of the physical brain. This materialistic psychology was supported by John Watson (1916), who wrote that psychology is a purely objective experimental branch of science that needs no consciousness in the same way that science does not need chemistry and physics. It is ironic that while Watson links psychology to the classical physical knowledge of Newtonian physics, there is overwhelming experimental evidence that the universe is related to quantum physics that could not be made without reference to consciousness.

John Lorber (1978) specialized in children with hydrocephalus, or water on the brain is a British neurologist. Children with this condition have an abnormal amount of cerebral spinal fluid accumulation in the cavities inside their brain compressing brain tissue that usually leads to mental retardation seizures, paralysis and blindness and if not treated to death. However, Lorber describes dozens of children and some adults with severe hydrocephalus but live normal lives. Indeed, in a sample of children with their cerebral space filled with ninety-five percent of spinal fluid in their skull leaving virtually no room for any brain tissue, half of them had a higher IQ than one hundred and thirty.

Some of the best evidence that consciousness can function independently of the brain come from near death experiences, profound experiences that some people report when they have been on the threshold of death. The near-death experiences are very short stories of people who have been clinically dead and then are resurrected or revived spontaneously after a brief interval with the memory of what they experienced during that period. According to Greyson (2010), many people with near death experiences reported vivid mental clarity exceptional sensory imagery and a clear memory of the experience and an experience that is more real, then in their daily lives. 


\section{Quantum Biofeedback}

As the traditional biofeedback, uses sensors to monitor physiological relaxation indicators as the temperature of the skin and muscle tension, quantum biofeedback expands classical biofeedback by using galvanic skin response (GSR) and other similar devices together with modern computer technology to detect and measure the response of the built-mind-spirit body (sometimes called the super-conscious) to a large array of stress indicators.

Quantum Biofeedback is a sophisticated biofeedback technique based on advanced scientific principles that promote a deeper understanding of health and healing. By seeing the body as a complex electrical circuit and by applying the principles of electrical engineering, weareable to analyze and balance the electric body. We usually think of the body as just anatomy and physiology; however, one of the easiest way to learn about the state of health of the body is by measuring electrical properties of the electric body.

Super-conscious makes adjustments to biological speeds to reduce internal tensions and sends 'back feedback' that allows the practitioner to focus the session on the parts of the body-mind-spirit more in need of relaxation. The result is a smooth passive relaxation session, still focused on those areas most in need of attention. When the body becomes so relaxed, the therapist can start the natural healing process. Many long-term stress cases can be reduced with biofeedback sessions.

Quantum Biofeedback interacts with all cellular matrix of the body, which allows communication with the conscious and unconscious reactions of the body. This is accomplished by establishing electrical communication using 12 electrodes that are attached to the head, wrists, and ankles of the client. Classic Biofeedback is based on electrical measurements taken from the front (frontal cortex). This information is presented to the users who then try to consciously change his or her internal reactions to modify electrical results. Quantum Biofeedback uses people's link to all body cell matrix interface, not only the conscious aspects, but also with the unconscious, this provides greater gain in the understanding of health.

Users of this technology experience increases in physical health, strength and stamina, they can also display more confidence, they may find it easier to sleep, which can be more relaxed, and they may experience more happiness and satisfaction in a day-to-day basis (Bennet et al. 1985).

Today, thousands of doctors and medical researchers worldwide are investigating electro medicine and biofeedback neurotechnology devices as effective traditional methods of treatment alternatives. These pathways are new possibilities for the treatment of conditions such as spinal cord injury, muscular restoration, nerve regeneration, brain stimulation, bladder disorders, tumors, heart disease and other chronic diseases and disorders.

\section{Transpersonal Psychology.}

Transpersonal Psychology considers that the psyche is multidimensional. There are several "levels of consciousness" and each has different characteristics and is governed by different laws. Transpersonal psychology does not deny other schools of thought as psychoanalysis does not arise as opposed; the right thing would be to say that attempts to go further. For transpersonal vision, Freud developments have been of fundamental value in the development of psychological science 
to include the idea of the unconscious in a discipline that was tied to the positivist rationalism. Certainly, psychoanalysis opened the possibilities of understanding the human psyche. Transpersonal psychology integrates the spiritual experience within a broader understanding of the human psyche.

It is with the study of states of consciousness and the full potential of man, that transpersonal psychology assumes that humans can achieve harmony and transcend through spiritual development. Transpersonal is something that exceeds the range of human's own experience or personal history. Transpersonal refers to that which is beyond of the person who is the essential being.

Much of its discoveries and contributions come from the study of Eastern religions, and Christian mysticism. Transpersonal psychology is interested in the different forms of Buddhism, for meditation, for yoga, for mystical experiences, psychophysiological effects that all these phenomena, the limits of consciousness, etc. The ultimate goal of all this is to try to achieve an awakening that is the greater awareness that would raise the level of "being" that integrates psychology and spirituality.

Transpersonal psychotherapist Anthony Sutich (founder and first editor of the Journal of Transpersonal Psychology) provides one of the first formal definitions of transpersonal psychology in 1969 at the inaugural edition of the Journal of Transpersonal Psychology (Vol. 1, No. 1, Spring 1969). "The emerging Transpersonal Psychology refers specifically to the empirical, scientific study, and the responsible application of relevant results, becoming meta-needs individual and specieswide, the final values, conscience unitive, peak experiences, values, ecstasy, mystical, amazing experience, being, self, essence, joy, wonder, ultimate meaning, transcendence of self, the spirit, unity, cosmic consciousness, synergy of individual and species level, maximum interpersonal encounter, sacralization of everyday life, transcendental phenomena, self-cosmic humor and joy maximum sensory awareness, responsiveness and expression; and concepts, experiences and activities " (Sutich, 1969).

Stanislav Grof, co-founder of transpersonal psychology with Abraham Maslow, defines transpersonal psychology as "The psychology that respects the entire spectrum of human experience, including holotropic states, and all domains of the psyche. - Biographical, perinatal and transpersonal "(Grof, 2000).

Transpersonal psychology covers a multitude of experiences and behaviors produced by spontaneous or altered states of consciousness, impulses into higher states of being, and extraordinary spiritual practices induced. Transpersonal phenomena include the meditative experiences, dreaming, drug-induced psychedelia, peak experiences, cosmic consciousness, enlightenment, mysticism, out of body experiences, channeling trance, near death experiences, memories reincarnations, extrasensory awareness, archetypal phenomena, accelerated learning, exceptional state of health and well-being, the mind-body healing and miraculous cures. Parapsychological phenomena is important for the reduction of science and spirit implications.

\section{Altered states of consciousness and transpersonal psychology}


Ludwig (1966) defines an "altered state of consciousness" as any mental state (s) for various manoeuvres of physiological, psychological or pharmacological agents, which can be recognized subjectively by the same (or an objective observer of the individual person induced) as representing a sufficient deviation in the subjective experience or psychological functioning of certain general rules for that individual during alert awareness. This deviation can be sufficiently represented by a greater concern than usual with internal sensations or mental processes, changes in the formal characteristics of thought, and the deterioration of the test of reality to varying degrees.

The cognitive approach to altered states of consciousness has revealed that similar features that are characteristic of many altered states of consciousness including "alterations in thinking", "sense of disturbed weather", "loss of control", "change in emotional expression "," change of body image, "" perceptual distortions "," change in the meaning or importance "," sense of the ineffable, " and " feelings of rejuvenation "(Ludwig 1972).

By applying the disruptive force requirement for the basic state of consciousness (either through some physiological action, such as drugs or deployment of attention and meditation), the current organization of cognitive subsystems is destabilized until a new force patterns (such as mental set, setting, expectations, drug effects) is applied to shape the subsystems in a whole new system, the production of a new discrete state of consciousness with its own stabilization processes.

Cognitive awareness approach has helped differentiate transpersonal psychologists' grades waking state of consciousness. Awareness, for example, is not one homogenous thing, but varies and changes as the colors of the rainbow. It is possible to stratify and states order to raise awareness of alert and focused relaxed concentration and spread the cosmic consciousness. A range of altered states of consciousness have been identified as drug-induced states, hypnosis, biofeedback, daydreaming, night dreaming, sensory deprivation, and paranormal experiences. With each state consisting of many levels and functions, in each region or area of consciousness, individuals are able to process different types of information at different levels of control (Goleman \&Davidson, 1979; Ornstein, 1972).

Transpersonal psychologists tend to see the experiences of "mystical union", "enlightenment", "nirvana", and related experiences as natural and beneficial non-ordinary states of consciousness that may be subject to effects of state-dependent learning. The idea that the experience of the sacred can be interpreted as altered states of consciousness arose from the observation of twice that (a) psychedelic drugs have been used through the centuries and cultures to induce religious experiences and (b) reports from some drug experiences are phenomenologically (descriptively or experiential) indistinguishable from accounts of natural mystical experiences (Doblin, 1991, Grinspoon \& Bakalar, 1997; Smith, 1964).

Transpersonal psychologist Charles T. Tart has examined the altered states of consciousness from a cognitive perspective in terms of changes in the configuration and operation of the underlying mental processes (Tart, 1971, 1976, 1983, 1992). A state of consciousness involves cognitive functioning following subsystems: exteroceptors (receives sensory information), interoceptors (kinesthetic receives input), input processing (working memory), the subconscious processes, sense of identity, evaluation and decision making, emotions, space / time sense, long term memory, the motor output (behavior) plus latent functions. These 10 subsystems (more possible latent functions) define any discrete state of consciousness. The particular configuration of the subsystems in a given time is shaped and limited by the deployment of attention, the body's 
energies, characteristics of the structures themselves and the particular social and cultural environments in which they operate.

Grof (1988) suggested that the term "altered states of consciousness" cover transpersonal experiences; however, there are certain types of altered states of consciousness that do not meet the criteria for being transpersonal (involving an expansion or extension of consciousness beyond the limits of the usual and limitations time and space). For example, a living and complex childhood memory occurs in an altered state of consciousness (e.g hypnosis or psychedelic sessions), but do not meet the criteria for being transpersonal.

The cultural context of the 1960s and 1970s provided fertile ground for the emergence of transpersonal studies as an independent field of study in psychology. The infusion of ideas Eastern contemplative traditions of Zen, Advaita, Vedanta and Taoism, along with the institutionalization of the humanist revolution in academic psychology, and the growing interest in consciousness and altered states of consciousness that are triggered by the widespread use of psychedelics, paved the way for the birth of transpersonal psychology movement in California in the late 1960s (Ferrer, 2002).

Since the 1970s, transpersonal psychology, as the humanist movement that preceded it, has been divided into three different groups; the first group represented by the ideas of Grof (1988) that believes that transcendence can only occur in the presence of a altered state of consciousness. This group produces conceptual models of non-ordinary states of consciousness. The second group, led by Wilber (1975), include those trying to assign internal states of consciousness and identify with the monistic and perennial philosophy of Aldous Huxley. Wilber believes that all expressions of the highest state of consciousness in each tradition are the same as the psychopathic conditions occurring at the bottom, the normal waking reality in the middle and meditative states of higher consciousness in the top. The third and by far the largest segment of the transpersonal movement has no identifiable bearer, it sees the self as getting up and go to work in the morning, the higher consciousness is sweeping the floor, washing dishes, and raking leaves. The lighting is doing everything we are supposed to be doing at this minute. There is a preconceived thing; is not an altered state of consciousness, it is simply the deep philosophy, which is to be found most clearly in the mundane (Taylor, 1999).

Altered states of consciousness answer the question "who we really are?" The answer to this question is that we are a part of God and that humans are spiritual beings having human experiences that somehow reveal the direction of our full identity of our cosmic status.

\section{Brain waves}

Our brain works primarily with bioelectrical energy. Although the power of electricity that handle our neurons is low (measured in mill volts), this power processes, manage, distribute and use vast amounts of information and generates multiple answers (almost infinite in possibilities). So by using micro electricity, we can conclude that the brain is a machine of low frequencies. Our brain, in addition to process information that comes by the senses, is capable of emitting extra-sensory information received via similar "electromagnetic waves", but with lower intensity similar to the frequencies of a radio transmitter-receiver. Our brain can act as a radio station, similar to numerous species of birds that in their migrations are guided by a genuine receiver of terrestrial 
magnetism located in the pituitary gland. With this receiver, they know where they have to fly and in what direction. It's like having a real compass incorporated into the brain. The mind could be defined as the "sense" of the brain (like sight is the sense of the eye).

A German psychiatrist, professor at the University of Vienna named Hans Berger (1.843-1941), demonstrated that a device "amplifier" that was called later electroencephalograph could captureelectrical potential (voltage fluctuations) in the human brain. Before him, the English physician Richard Caton (1842-1926) showed similar potential in dogs. The first types of brain frequencies that were discovered were the "alpha" and "theta".

Later, these findings were complemented by research in the range frequencies captured by the electroencephalograph. Each type of wave results in a different neuropsychological state. That is, our mind, our body and our physical and physiological activity are completely different in each of these states or frequencies. The type of neuro-chemicals and hormones substances discharged into the blood flow varies depending on frequency and as much as the presence and quantity of such substances as the mood we have, interact to produce a physiological-mental-physical-end that involves a mental state. A level of consciousness is conscious thought that is always thinking even in moments of apparent inactivity, but trivial ideas continually pass by consciousness. Most of the thoughts are accompanied by reactions in behavior, and small involuntary movements. When you're not actively thinking then you're probably dreaming, according Signer and Streiner (1966) a person has throughout the day about 200 daydreams. Therefore consciousness is the sum of all the different perceptions. The most common consciousness are wakefulness and sleep; however, changes in expressing both cerebral and psycho states change according to conscious or subconscious feelings of each person are distinguished. These changes are directly related to the electrical activity of the brain. This activity can be measured by the number of oscillations per second $(\mathrm{Hz})$ that are linked todifferent states of consciousness in the brain: our brain only perceives a limited range of frequencies indispensable to operate with ease in this three-dimensional medium. 20 to 20,000 vibrations per second are perceptible by our ears, the colors perceived by our eyes range from red to violet (although extending beyond, up and down), all possible smells and tastes (which are also vibrations) and the endless textures that we can distinguish with our skin. But the brain is not only receiver but also is sends vibrations. It has been proven thanks to the EEG that the brain emits waves of varying intensity and frequency depending on the mental state of the person being observed. These waves are classified into:

\section{Table 1 Types of Brainwaves}

\begin{tabular}{|l|l|}
\hline TYPES OF BRAIN WAVES & STATES OF CONSCIOUSNESS \\
\hline BETA WAVES: 14 Hz to 30 $\mathrm{Hz}$ & $\begin{array}{l}\text { This type of waves are recorded when the } \\
\text { person is awake in a state of normal activity. } \\
\text { Correspond to states of conscious attention, } \\
\text { anxiety, surprise, fear, stress. }\end{array}$ \\
\hline GAMMA WAVES : 25 and $100 \mathrm{~Hz}$ & $\begin{array}{l}\text { They express pathological conditions of } \\
\text { maximum tension, excitement and the } \\
\text { individual enters a state of STRESS in which the } \\
\text { coordination of ideas and normal physical } \\
\text { activity are seriously altered. }\end{array}$ \\
\hline
\end{tabular}




\begin{tabular}{|c|c|}
\hline ALPHA WAVES: $8 \mathrm{~Hz}$ to $13 \mathrm{~Hz}$ & $\begin{array}{l}\text { Relaxation and rest, calm, reflective state. } \\
\text { Reduction of bodily sensations. The } \\
\text { subconscious begins to emerge: Abstraction, } \\
\text { suggestibility. Assimilation of the study. Ease of } \\
\text { visualization of mental images. }\end{array}$ \\
\hline THETA WAVES: $3.5 \mathrm{~Hz}$ to $7 \mathrm{~Hz}$ & $\begin{array}{l}\text { During sleep or in deep meditation, autogenous } \\
\text { training, hypnosis, yoga (whenever the } \\
\text { formations of the subconscious act). The state } \\
\text { stimulates creative inspiration. Considered a } \\
\text { state for maximum capacity of learning. Fantasy, } \\
\text { imagination. Hypnagogic images. }\end{array}$ \\
\hline DELTA WAVES: $1 \mathrm{~Hz}$ to $3 \mathrm{~Hz}$ & $\begin{array}{l}\text { It arises mainly in the states of deep sleep and } \\
\text { unconsciousness. Very rarely can be } \\
\text { experienced being awake unless with a very } \\
\text { hard training (Yoga, Meditation, Zen, Hypnosis, } \\
\text { Self hypnosis) or with a synchronizer of } \\
\text { hemispheres. It corresponds to deep sleep, } \\
\text { hypnotic trance, REM sleep. It corresponds to } \\
\text { sleep without dream, trance, deep hypnosis. } \\
\text { Delta waves are very important in the healing } \\
\text { process and strengthening the immune system. }\end{array}$ \\
\hline
\end{tabular}

The alpha state is when, if we would connect to an electro encephalogram, our brains would work between 7.5 to 14 cycles per second. When "operate" in this state, we rank among the border of the conscious and the unconscious. Is the gate between both states of consciousness and this makes "Alpha state" therefore a special status because it allows us, on the one hand, still have a conscious activity of our mind and body, that is, we realize what we think and happening around us. On the other hand, since the "lift" of consciousness in the "lower floors" of the mind, gives us access to information and own subconscious states, can use all the wealth of the $90 \%$ of "power" mental residing in the subconscious. This state is a "being comfortable" in inner peace and happiness, in deep relaxation. Greatly increases the power of suggestion and auto-suggestion, that is, anything that we suggest alpha, will be more easily accepted and less "filters" by our conscious rationality.

Music is a very effective instrument of suggestion and production of alpha state made many instruments produce vibrations at that frequency. Hence, with relative ease, many people stay asleep at concerts or simply feel "moved" by the music to another dimension. If we put them to an electroencephalograph, most of those attending a concert in an auditorium would be running on alpha. The contemplation of the sea, the rolling waves and the sound they produce is a good inducer of alpha state. The tone of individuals things like music, prayer, smells, certain types of images (especially of nature, certain types of painting, Tibetan mandalas symbols or own) can be used to put ourselves in this special state of the mind, that makes us touch our innermost and reach the 
"spiritual zone" of human beings. Therefore, as we see, there are many things that can induce this state.

Magnus \& Van der Holst (1987) speak of frequencies whose frequency ranges from 3.5 to 7.5 cycles per second. They are associated with the states of creative and decisive hallucination. During its broadcast, the person can discover events deeply hidden in the recesses of your subconscious, as well as conflicts and personality in particular. Is the wave of imagination and dynamic contact with other possible "dimensions psi" offering you the opportunity to research our personality and deep in our psychology.

\section{Neurotechnology principles}

Robert Monroe (1982), one of the most prominent people in neurotechnology in particular in the field of sound with neurological efficiency, devised the method HEMI-SYNC: (Synchronization of the cerebral hemispheres by means of sounds). Like a glass that resonates when a pure tone is emitted, the brain resonates when receives certain frequencies of waves, being synchronized with these, this effect is known as FFR Frequency Following Response (FFR).

Machines created based on FFR began to be popular in the 80s, the typical machine based on the principle of Monroe used stereo headphones that are used to send sound signals to each ear, for example 2 signs of 300 and $304 \mathrm{~Hz}$. One ear will hear only $300 \mathrm{~Hz}$ signal and the other only 304, but since the sounds are combined in the brain, this will hear a third signal of $4 \mathrm{~Hz}$ which is the difference between the two sound impulses. This third signal is not an audible sound, but an electrical signal that can only be created by the cerebral hemispheres acting in unison, and may go unnoticed, producing as a result, the two hemispheres are focused simultaneously on the same state of consciousness, increasing the brain power.

The Monroe Institute was created based on the principles of Monroe. The neurotechnology of the Monroe Institute is a system that mixes and sequences sound patterns designed to evoke beneficial brainwave states for different human activities. This institute was founded by Robert A. Monroe, who began studying the effects of sound on accelerated learning in the 50s. The work is the result of thousands of hours of laboratory sessions. Participants in these sessions listen to specific combinations and sequences of sound patterns and simultaneously report their experiences while electronic instruments measure the effects on the activity of their brain waves.

Walter (1964) while conducting experiments in which strobe devices used to send rhythmic flashes of light in the eyes, watched amazed that the flickering light could alter the activity of the entire cerebral cortex, rather than exclusively associated areas with vision. The subjective experiences of those who received the flashes were even more curious reported seeing "lights like comets, ultra fantastic colors, color mental". Moreover, Walter discovered that certain visual stimuli of a certain frequency could cause the brain to respond quickly adjusted to the same frequency of the stimulus it received.

In 1982 a psychiatrist Denis Gorges created a machine called brain wave synchro- energizer, which applies the latest technology in the first device designed optical-acoustic stimulation. This is able to promote as its inventor claimed "an increase in the capabilities and functions of the human mind", 
this unleashed a wave of unprecedented research and experimentation, catalyzed by M. Hutchinson (1986) through his famous book Megabrain.

Our scheme of thought is influenced by the predominance of left hemisphere, logical and analytical thinking. Right hemisphere, creative thinking, visualization, and which carries out a holistic synthesis. On the back of the brain is where the intuitive thought takes place. Obviously use one of the two hemispheres or either of the brain regions severely limits our abilities. The optimal functioning of our brain, is given by the synchronization of the two hemispheres: by left-right and front-back alternating stimulation occurs almost simultaneously, an issue of brain wave of an identical amplitude and frequency. Neurotechnology is typically used for process brainwave entrainment to tune brainwaves. With these machines, we may experience theta waves, alpha, delta or including combinations of ranges using frequencies layered that mix several brainwave ranges in a synergistic pattern.

Hemi-Sync is a patented process sound that pulses to create the same electric waves in frequency and amplitude simultaneously in both hemispheres of the brain for specific purposes. Our brains have a hemisphere left and right. The left brain is linear, logical, practical, and time -oriented. The right hemisphere seems to be much more nonlinear, abstract, creative, holistic, and not logic. We tend to use one hemisphere at a time, or better said, will favor hemispheres particular in terms of what we're doing. An accountant probably uses less of his right hemisphere than an artist would during the course of his workday. If the person is doing math, the staff would be using more of your left side. If the person is going to paint a master piece of art, the person would have the activity hemispheric more in the right. Both hemispheres are constantly interacting and both can be used simultaneously.

By merging both hemispheres we can make them to work together and with this we can increase our ability mental and improve our performance cognitive in general. Basically it's like having a computer processor faster able to work at faster speeds. The greater integration creates better performance.

The mind machines that help the brain synchronizes naturally to balance hemispheric activity and adjusts the activity of brain waves to match the carrier frequencies embedded brainwaves. This hemispheric coherence induced audio produces an optimal state of comprehensive synergy of the entire brain. These hemispheres are connected by the corpus callosum that it serves as a conduit or a bridge between both sides. This bridge literally be exercised and strengthened until it is physically larger and more capable of transmitting data, ideas and feedback between the hemispheres.

The advance occurs when you use this principle to synchronize our brain wave frequencies chosen with the help of specific mental machines. We can do this easily by using technology of binaural beat audio and monophonic ringtones. This phenomenon is called trailing phenomenon.

The scientific principle of drag can be used to resonate, or synchronize our brain to tune specific frequencies. The drive is quite simple. If we have two tuning forks of the same pitch, if we strike one and hold it near the other both resonate at the same frequency. Given the fact that our brains function as a resonating chamber, oscillating pulses and patterns of neural excitation ripple through our brains like endless waves on a pond of a subtle dynamic electric field. 
The creation process of frequency binaural beat is very simple to explain. First, we create two audio tones with two frequencies slightly different (ie $100 \mathrm{~Hz}$ and $107 \mathrm{~Hz}$ ). When playing a tone in the ear left and the other tone in his right ear, the brain reacts to the stimulus audio by resonance brain activity to the difference between these two tones. Our brain waves adjust to match this frequency differential. For example, if we play a frequency of $100 \mathrm{~Hz}$ in the ear and left $107 \mathrm{~Hz}$ in the right ear, our brain tune the $7 \mathrm{~Hz}$ differential ( $107 \mathrm{~Hz}-100 \mathrm{~Hz}=7 \mathrm{~Hz}$ ). This frequency tracking response makes our brain to resonate at $7 \mathrm{~Hz}$ frequency and this falls within the range of theta brainwaves. This psychoacoustics state can create phenomenal results.

The electrical activity of neurons is changing patterns of electrical potential through all cell membranes. Each cell generates in the membrane potential that can be detected in about one micrometer of the cell and in large sets of brain cells that can work in harmony to generate potential of few micro volts, this can be detected through the skull and scalp by using electrodes. The variation of the electrical potential around the scalp is the basis of operation of the electroencephalogram (EEG). This method of recording the electrical activity of the brain, digitized maps produces the electrical activity of brain.

The state in which the two hemispheres are synchronized by showing similar activity in both hemispheres, is sometimes known as "whole brain" and occurs randomly for short periods. Stimulation through the differential tone makes it possible to sustain this state for longer periods.

The Hemi-Sync process has already been tested and implemented in many ways for:

- sleep better

- reduce tension or stress

- control pain

- accelerate learning

- study and concentration

- enhance creativity

- $\quad$ find solutions to problems

\section{The induction and measurement of altered states of consciousness by using neurotechnology in transpersonal psychotherapy}

The most frequently heard of studies of altered states of consciousness criticism is that they are hoaxes, some form of mental delusion. A good example is the case of Eastern yogis who for years claimed to be able to control parts of the nervous system and the body such as heart rate, blood pressure, hormone secretion, etc. These claims were considered impossible by western scientists whose theories and personal experience denied this possibility.

Biofeedback research shows that many of the claims made by physicists yogis, particularly the state of consciousness can be changed at will by changing the sound pattern proved to be true. EEG measurements have been based on the research and theories developed from the early work of Adrian and Matthews (1934) that discovered that the brain could go to certain frequencies with electronic brain stimulation, this work led to the discovery that various frequencies were linked to certain psychological states (Kamiya 1968), and ultimately the work of Green et al. (1977) 
demonstrated the ability to control these states and frequencies. You could say that these tests were the first to show how the brain can boot, such as a computer with the right input frequency.

What exactly happens neurologically when we walked into alternate states of consciousness is still far from being understood. This gap in our knowledge of these kingdoms is largely due to deficiencies in both research tools and philosophies employed by scientific research, and our general reluctance of society to accept such states as real. Within the traditional scientific practice is important to understand how our brains create the bridge to stimulate altered states of consciousness, but understanding it tells us little or nothing about the correlation with psychological phenomena with which we are able to interpret altered states of consciousness. It is this inner cosmological view or its representation of our quantum reality.

Once we accept this premise as our fundamental metaphor for altered states of consciousness, then it is possible to postulate that our brainwave frequencies are measurement indicators of our psychological states and correspond to the various ways in which we produce. That is, these frequencies are the units of our quantum reality. This is how we create, outside the sphere of influence of the Heisenberg principle that says that our fields are a unified experience.

Cade et al (1979) conducted EEG tests in 70 subjects and measure the ESR (electrical resistance of the skin) and with the application of its results to the work of Terry Lesh (1970) was able to build in the table below that represents the objective and subjective correlates of these states.

Table 2 states of consciousness and frequency measurements

\begin{tabular}{|c|c|c|}
\hline Consciousness & Measured frequency & Types of waves \\
\hline $\begin{array}{|lr|}\text { Just he is beginning to } \\
\text { relax with } \\
\text { quieting } & \text { difficulty } \\
\text { mind. } & \\
\end{array}$ & $25-20$ & alpha and beta \\
\hline $\begin{array}{l}\text { Not very clear conscience } \\
\text { or sense of anesthesia }\end{array}$ & $20-16$ & $\begin{array}{l}\text { Guests } \\
\text { alpha continuous }\end{array}$ \\
\hline $\begin{array}{l}\text { Calm and relaxed with } \\
\text { memories }\end{array}$ & $16-13$ & $\begin{array}{l}\text { Alpha continues } \\
\text { without } \\
\text { theta intermittent }\end{array}$ \\
\hline $\begin{array}{|lr|}\text { State } & \text { definite } \\
\text { feeling of } & \text { floating with } \\
\text { increased } & \text { imagination } \\
\text { and } & \\
\text { more } & \text { concentration } \\
\text { sustained } & \\
\end{array}$ & $13-10$ & $\begin{array}{l}\text { Alfa falling } \\
\text { Continuous theta }\end{array}$ \\
\hline $\begin{array}{l}\text { Living consciousness the } \\
\text { body modification } \\
\text { between awareness } \\
\text { internal and external }\end{array}$ & $10-8$ & $\begin{array}{l}\text { alpha continuous } \\
\text { theta falling Frequency }\end{array}$ \\
\hline Awareness $\quad$ with & $8-5$ & continuous \\
\hline
\end{tabular}




\begin{tabular}{|l|l|l|}
\hline $\begin{array}{l}\text { satisfaction and deep } \\
\text { intense alertness } \\
\text { and calmness and } \\
\text { detachment }\end{array}$ & alpha close to theta \\
\hline $\begin{array}{l}\text { New way of feeling by } \\
\text { intuitive vision } \\
\text { synthesis of opposites } \\
\text { in a higher unity }\end{array}$ & below 4 & Delta occasionally \\
\hline
\end{tabular}

One of the determinants of the results of the induction of altered states of consciousness in psychotherapy comes from Penfield and Perot (1963) who developed a study where a series of what was called in those days outside the body psychic visions were caused a that emerged not only for his epileptic patients but also in patients who had at the operating table for which they stimulated the surface of their brain. In one case study,one of his epileptic patients actually had visions of God descending from heaven .

An important factor in the development of neurotechnology step was carried out by Persinger (1983), Persinger is the director of the neuroscience program at Laurentian University. Persinger (1983) is able to induce visions of God and other religious and mystical experiences in the laboratory by using a computer and what he calls the koran helmet that was also given the nickname God helmet. His most important contribution to the induction of altered states of consciousness came when he had a vision as to the origins of spirituality in human evolution. He found that the temporal lobes of the brain are the source of most spiritual and mystical experiences of the scientific literature.

The God helmet is a device used to induce altered states of consciousness using weak magnetic signals to direct brain activity. This can induce spiritual experiences and helps auto wing transpersonal exploration and transformation of many people. Persinger (1983) investigated some common perceptions of the inner mind by taking electromagnetic brain patterns seen in people who have near-death experiences. Persinger (1983) found that it can simulate that by applying complex significant magnetic fields in the brain that can also induce altered state of consciousness such as near-death experiences. Persinger et al (2000) conducted an experiment that tested the idea that mystical perceptions and paranormal experiences can be triggered by stimulating the nerve activity in the brain. In the experiment, volunteers were blindfolded in a soundproof chamber, this sensory deprivation allowed the mind to concentrate on electromagnetic patterns sent through the brain via a modified helmet. In the experiment, they were able to simulate the exact brain patterns that occur in near-death experiences.

Dr. Persinger (2000) suggests that his research will benefit psychotherapy by producing altered states of consciousness including near death experience, hearing voices and the sense of a presence as patients will able to deal with things like psychological depression by experiencing these altered states. Persinger (2000) suggests that these experiences are so strong that they are completely real to the person who has them. As a tool of science, the God helmet technology can bring us valuable new insight into the dark depths of the human mind.

Persinger (1983) conducted experiments of the type of stimulation of the low level temporal lobes of the brain, in order to induce altered states in the subject in the experiment. After an initial feeling of floating in the air, the individual was feeling 'out of body'. Then the experiments used different 
subjects but whose constant is to describe their feelings with cosmic and spiritual meanings. Persinger mentions "Often intense listening experiences in which the person feels that some messages are communicated to him occurs". This transmission is perceived by the individual through a kind of feeling of "knowing what happens" without being able to necessarily say that hears a voice. Persinger suggests that people with epilepsy, (temporal lobe dysfunction), are more likely to experiment altered states.

With the aid of neurotechnology, people can discover hidden deep subconscious events as well as conflicts of personality offering the opportunity to research our personality and discover the depths of our psychology. Green, et al. (1970) mentioned that "every change in mental-emotional state, conscious or unconscious, is accompanied by an appropriate change in the physiological state". Our travels along with the continuous-consciousness is manifested by a wide range of psychological and physiological changes, inducing altered states of consciousness take our mental functions to places normally out of reach of our everyday consciousness, these areas are usually reserved for religion, mysticism and ingestion of psychoactive substances. The experiences one is on a journey through the fall of consciousness into the realm of psychological experience known as the transpersonal, these transpersonal experiences are such that exceed normal limits of our existence and leave the empirical way of knowing, initiating human consciousness in a meeting with those areas of consciousness that are, in normal conditions, being largely inaccessible to us. This process of leaving the empirical normal physical limits of our existence seems to serve as further proof of what was described in this paper before that religious, mystical and philosophical thought are related to quantum physics.

When individuals use neurotechnology using the phenomenon of entrainment in the brain for days or weeks in a row, the out of body experience seems to be more the rule than the exception. Normally these experiences manifest as spontaneous feelings flying above a landscape. It is nothing strange that the same feeling out of the body that occurs in many different practices aimed access to altered states of consciousness as well as show as the main subject of near-death experiences. The timing and the subsequent stimulation of the two hemispheres of the brain entrainment can result with the use of nerotechnology as Fischer \& d'Aquili (1986) suggest.

Much of what appears to take place within the transcendental experience of parapsychology, seems to be what many of us commonly called the synchronicity. The synchronicity can be defined as a causal connecting principle of coincidence of events in space / time. Carl Jung, who is the first to describe the concept of synchronicity, saw that this state could be related to many transcendental experiences. These synchronistic events can be linked dreams, visions, meditative states and other inner experiences with tangible events in the life of the subject.

A growing number of professional researchers postulated that ESP can be linked to the alpha state (Lawrence, 1972). Dr. Edward Bokert of the American Society for Psychical Research, analyzed mental states and has concluded that they are, at least in its early stages, "characterized by a highly aroused autonomic nervous system" (Lawrence, 1972 ) precisely what one finds in the ergotropic excitement associated with the brain and the use of neuro technologies.

Dr. Charles Honorton of the Maimonides Medical Center has also found that the ESP seems to be associated with "relaxation, mild dissociation, passivity, and reduced visual imagery" (Honorton, 
1970), which is commonly found when waves alpha occur with brain entrainment technologies. Indeed, Honorton found that the higher alpha production, the higher the score obtained in the individual tests ESP. It seems as if many of the psychic states that identified Grof as part of the "Experiential Extension Beyond the consensus reality and space-time" may be associated with changes in one level of consciousness to another.

\section{CONCLUSIONS:}

Our present understanding of "brain entrainment technology" is still in its infancy, however, this article intends to open the eyes of the reader that this technology has great potential particularly for transpersonal therapies.

This article introduced neurotechnology based technologies including quantum biofeedback; the latter has proven curative value for particular diseases that seem to be psychosomatic and also has been proven to help to measure state of consciousness of individuals. Transpersonal psychology was presented as a paradigm that recognizes the immortality of consciousness and relies on spiritual concepts that have roots in mystic religions as reincarnation and survival of consciousness after the brain death. The immortality of consciousness is based largely on the quantum theory explaining the origin of consciousness and its connection to the universe.

Neurotechnology explores the use of technologies of sound, light and radiofrequency to control the frequency of brain waves with the reason to induce altered states of consciousness. Altered states of consciousness have been proposed as therapies for healing in transpersonal psychology, these therapies recognize the spiritual essence of the individual and are based on the concept that psychological illnesses are rooted in the spirit and not in the brain. Once the patient knows the root of his or her problems, seems to find the answer to his or her anxieties and can self heal with these transpersonal experiences.

Inducing altered states of consciousness with Neurotechnology is a relatively new concept and although there are serious studies, they are not incorporated into traditional medicine more than anything by a lack of understanding of this technology in traditional medicine. The aim of this paper

is to open the eyes of thetherapists about the potential of these technologies in the use of transpersonal therapies.

\section{REFERENCES}

Adrian E and Matthews B. The Berger Rhythm; potential Changes from the occipital lobes in man. Brain 1934; 57(1): 355-384.

Becker R and Selden G. The Body Electric: Electromagnetism and the foundation of life. Quill: New York, 1985.

Cade CM and Nona C. The Awakened Mind: Biofeedback and the Development of Higher States of Awareness. Delacorte Press: New York, 1979.

Doblin R. Pahnke's. "Good Friday experiment": A long-term follow-up and methodological critique. Journal of Transpersonal Psychology 1991; 23 (1):1-28. 
d'Aquili E . The Myth-Ritual Complex: A Biogenetic Structural Analysis, Zygon 1983; 18(1): $247-$ 269.

d'Aquili, E. Myth, Ritual and the Archetypal Hypothesis, Zygon 1986; 21(2): 141-160.

Edelman, GM and Tononi G . A Universe of Consciousness: How Matter Becomes Imagination. Basic books, 2000.

Ferrer, JN. Revisioning transpersonal theory: A participatory vision of human spirituality. Suny Press, 2002.

Green E and Alyce G. Beyond biofeedback. Delacorte, New York, 1977.

Grinspoon L and James BB. Psychedelic drugs reconsidered. Basic Books, New York, 1979.

Green E, Alyce G and Walters ED. Voluntary control of internal states: Psychological and physiological. Subtle energies and energy medicine 1999; 10(1): 71-88.

Greyson B. Dissociation in People Who Have near-death experiences: Their bodies out of or out of Their minds ?. Lancet 2000; 355 (9202): 460-463.

Greyson B. Implications of near-death experiences for a postmaterialist psychology. Psychology of Religion and Spirituality 2010;2 (1): 37.

Grof S. The Adventure of Self-Discovery . State University of New York Press,New Yotk, 1988.

Goleman D and Davidson RJ. Consciousness: Brain, states of consciousness, and mysticism. Harper, New York, 1979

Grof S. Psychology of the Future: Lessons from modern consciousness research. State University of New York Press, Albany, NY, 2000.

Hall CS and Vernon JN. A Primer of Jungian Psychology. Mentor Books, New York, 1973.

Hawnser PE. The Answer. Editorial Diana, Mexico, 1997.

Bennett JM, Catovsky D, Daniel MT, Flandrin G, Galton DAG and Gralnik HR. Lithotripsy. Health and Public Policy Committee, American College of Physicians. Annals of Internal Medicine 1985; 103(4): 626-629.

Honorton C. 1970. Tracing ESP through altered states of consciousness, Psychic Magazine; 2(18):78

Hutchison M. Megabrain: New tools and techniques for brain growth and mind expansion. Beech Tree Books, 1986.

Jonas WB and Levin JS. Essentials of complementary and alternative medicine. Lippincott Williams \& Wilkins, Philadelphia, Pa, USA, 1999. 
Jung CG. The archetypes and the collective unconscious (No. 20). Princeton University Press, New York, 1981.

Kamiya J. Operant monitoring of the EEG alpha rhythm and some of Its Reported effects on consciousness, In C. T. Tart (Ed.), Altered states of consciousness (pp. 519-529). Anchor Books , Garden City, N. Y.1969.

Lawrence J. Alpha Brain Waves . Nash Publishing. Los Angeles, 1072.

Liboff AR. Geomagnetic cyclotron resonance in living cells. Journal of Biological Physics 1985: 13(4), 99-102.

Ludwig A. Altered states of consciousness, Archives of general Psychiatry 1966: 15(3) 225-234.

Lorber J. Is Your Brain Really Necessary. Archives of Disease in Childhood 1978: 53(10), 834-834.

Magnus $\mathrm{O}$ and Van der Holst M. Zeta waves: a special type of slow delta waves.

Electroencephalography and clinical neurophysiology 1987; 67 (2):140-146.

Masters R and Jean H. The Varieties of Psychedelic Experience . Delta Books, New York, 1966.

Miller NE . Biofeedback and visceral learning. Annual Review of Psychology, 1978; 29 (1), 373-404.

Monroe R. The Hemi-Sync process. Monroe Institute Bulletin, \# PR31380H. Nellysford, VA, 1982.

Ornstein RE. The psychology of consciousness, WH Freeman, New York, 1972.

Persinger MA. Religious and mystical experiences as artifacts of temporal lobe function: general hypothesis. Perceptual and Motor Skills 1983; 57 (3): 1255-1262.

Persinger MA, Tiller SG and Koren SA. Experimental simulation of experience and a elicitation haunt of activity by paroxysmal electroencephalographic transcerebral complex magnetic fields: induction of a synthetic ghost. Perceptual and Motor Skills 2000; 90 (2): 659-674.

Penfield $\mathrm{W}$ and Perot $\mathrm{P}$. The brain record of auditory and visual experience a final summary and discussion, Brain 1963: 86 (4); 595-696.

Russell RJ, Murphy N. and Isham C J. Quantum cosmology and the laws of nature: scientific perspectives on divine action. Vatican Observatory, Italy, 1993.

Singer JL and Streiner BF. Imaginative content in the dreams and fantasy play of blind and sighted children. Perceptual and Motor Skills 1966; 22 (2): 475-482.

Smith H. Have religious import drugs do?. The Journal of Philosophy 1964; 61(1): 517-530.

Sutich AJ. Some Considerations Regarding transpersonal psychology. Journal of Transpersonal Psychology 1969; 1(1) ; 11-20. 
Lesh TV. Meditators Zen and the Development of Empathy in Counselors, Journal of Humanistic Psychology, 1970; 10(1):39-74.

Tart CT. Scientific foundations for the study of altered states of consciousness. Journal of Transpersonal Psychology 1971; 3(1): 93-124.

Tart CT. The basic nature of altered states of consciousness: A systems approach. Journal of Transpersonal Psychology 1976; 8(1): 45-64.

Tart CT. States of consciousness. Psychological Processes, El Cerrito, CA, 1989.

Tart CT. Transpersonal psychologies, American Psychological Association, Washington DC.1992..

Tornell H. The quantum man, editorial Diana, Mexico, 2001.

Wallace B and Fisher LE. Consciousness and behavior (3 rd . ed.). Allyn \& Bacon, Boston, 1991.

Walter WG. Slow potential waves in the human brain Associated With expectancy, attention and decision. European Archives of Psychiatry and Clinical Neuroscience 1964; 206 (3): 309-322.

Watson JB . The place of the conditioned reflex in psychology. Psychological Review 1916; 23 (2): 89.

Wilber K. Psychologia Perennis: The Spectrum of Consciousness, Journal of Transpersonal Psychology 1975; 7(2): 105-132.

Valverde R. Principles of Human Computer Interaction Design, Lambert Academic Publishing, Germany, 2011.

Valverde R. Channeling as an Altered State of Consciousness in Transpersonal Psychology Therapy. Journal of Consciousness Exploration \& Research 2015; 6(7): 405-416. 